\title{
Common fears of patients undergoing bronchoscopy
}

\author{
P.J.H. Poi, S.Y. Chuah, P. Srinivas, C.K. Liam
}

Common fears of patients undergoing bronchoscopy. P.J.H. Poi, S.Y. Chuah, P. Srinivas, C.K. Liam. (CERS Journals Ltd 1998.

ABSTRACT: In the world of medical literature, little has been reported about the fears of patients undergoing bronchoscopy.

The aim of this study was to identify the common fears of patients undergoing fibreoptic bronchoscopy and to determine whether any factors might contribute to reducing these fears.

One hundred and four consecutive patients undergoing bronchoscopy were interviewed.

Sixty one patients expressed fear about the procedure, as follows: afraid of pain (33); afraid of breathing difficulties (11); afraid of oropharyngeal irritation (5); afraid of the bronchoscopy findings (2); afraid of sedation, cross-infection and nasal lignocaine spray, respectively (3); and unable to be specific (7). There was no difference between the "no fear" and "fearful" groups in ethnicity, source of referral, education, previous endoscopy, doctors' explanation and the patients' understanding of the procedure and its indication. "Fearful" patients were significantly younger $(t=$ $2.082, p=0.037)$ and female $\left(\chi^{2}=4.180, p=0.038\right)$. Doctors were more likely to explain the indication for bronchoscopy than how it would be performed $\left(\chi^{2}=6.403 ; p=0.011\right)$, and patients were more likely to understand why they needed a bronchoscopy than how it would be performed $\left(\chi^{2}=21.505 ; \mathrm{p}<0.001\right)$.

Fear preceding bronchoscopy is independent of patients' demographic features except for age and gender. Doctors tend to explain "why" but not "how" the procedure is performed. Provision of detailed information about sensations that are likely to be experienced in bronchoscopy could be used to allay some of these common fears. Eur Respir J 1998; 11: 1147-1149.

Specific investigative procedures, such as bronchoscopy, are considered stressful to the patient involved. Patients who show the highest levels of response prior to the procedure tend to experience adverse psychological reactions postprocedure [1]. It has been recognized that there could be considerable gains from providing a psychological intervention designed to minimize the psychological impact of a medical procedure. These interventions include information provision. The type of information provided falls into two categories. Sensory information provides the patient with a description of the likely sensations that the patient might expect to feel, and procedural information describes what will happen during the procedure. Generally, information about sensations that are likely to be experienced has been found to produce more beneficial effects [2-3], particularly with distressing investigative procedures, such as endoscopy $[4,5]$.

Little is known about the fears faced by the patient undergoing a fibreoptic bronchoscopic examination. The aim of this study was to identify the fears of patients undergoing fibreoptic bronchoscopy and whether the patients' demographic features, their knowledge and understanding of the procedure and its indication, and their doctors' explanation contributed to reducing these fears.
Dept of Medicine, University Hospital, Kuala Lumpur, Malaysia.

Correspondence: P.J.H. Poi

Dept of Medicine

University Hospital

50603 Kuala Lumpur

Malaysia

Fax: 6037557740

Keywords: Fear

fibreoptic bronchoscopy

Malaysia

Received: April 211997

Accepted after revision January 281998

\section{Patients and methods}

The University Hospital in Kuala Lumpur, Malaysia, is an 880 bed acute general teaching hospital. One hundred and four consecutive patients undergoing bronchoscopy were interviewed, using a standardized questionnaire. These patients were recruited from the outpatient department and the medical and surgical wards, as well as direct referrals from the primary care department of the hospital. Consent was obtained from each patient by their attending doctor.

The patients received a short explanation describing the procedure and the reasons for having the examination 24$48 \mathrm{~h}$ before undergoing bronchoscopy. The authors personally interviewed and filled out the questionnaire with each patient in the waiting area of the endoscopy unit, 20-30 min prior to carrying out the procedure. Their age, gender, ethnicity, source of referral, inpatient/outpatient status, level of education, previous endoscopic experience and preference for sedation were recorded. The patients were asked to state their greatest fear about the procedure, without any prompting of the possible responses. The doctors' explanation and the patients' knowledge and understanding of the procedure and its indication were noted. 
Bronchoscopy was performed during the twice-weekly routine diagnostic bronchoscopy sessions by one of the authors, all of whom are experienced endoscopists.

The unpaired Student's t-test was used to compare the difference in age between the "no fear" and "fearful" groups. The Chi-squared test was used to compare their gender, ethnicity, source of referral, inpatient/outpatient status, level of education and previous endoscopic experience. A p-value of $<0.05$ was considered to be statistically significant.

\section{Results}

Forty three patients expressed no fears when questioned. Of the 61 patients who expressed fear, 33 were afraid of pain, 11 afraid of breathing difficulties, five of oropharyngeal irritation, two of the bronchoscopy findings and their implications, one each of sedation, cross-infection and nasal lignocaine spray, respectively, and seven were afraid but were unable to be specific. "Fearful" patients were significantly younger than patients who expressed no fear in undergoing the procedure $(\mathrm{t}=2.082 ; \mathrm{p}=0.037)$. Their mean ages (SEM) were 51 (2) yrs and 57 (2) yrs, respectively. Females were significantly more fearful than males $\left(\chi^{2}=4.180 ; \mathrm{p}=0.038\right)$. There were no differences between the "no fear" and "fearful" groups in terms of eth-

Table 1. - Comparison of demographic features between "no fear" and "fearful" patients

\begin{tabular}{lrrl}
\hline & \multicolumn{2}{c}{ Patients } & \\
& No fear & Fearful & Significance \\
\hline Sex & 33 & 35 & $\chi^{2}=4.180$ \\
Male $(\mathrm{n}=68)$ & 10 & 26 & $\mathrm{p}=0.038^{*}$ \\
Female $(\mathrm{n}=36)$ & 6 & 17 & $\chi^{2}=2.843$ \\
Ethnic group & 30 & 36 & $\mathrm{p}=0.240$ \\
Malay $(\mathrm{n}=23)$ & 7 & 8 & \\
Chinese $(\mathrm{n}=66)$ & & & \\
Indian $(\mathrm{n}=15)$ & 27 & 40 & $\chi^{2}=0.085$ \\
Status & 16 & 21 & $\mathrm{p}=0.768$ \\
Inpatient (n=67) & & & \\
Outpatient (n=37) & 33 & 48 & $\chi^{2}=0.055$ \\
Referrals & 10 & 13 & $\mathrm{p}=0.809$ \\
Medical (n=81) & & & \\
Nonmedical (n=23) & 6 & 33 & \\
Level of education & 6 & 11 & $\chi^{2}=1.958$ \\
Illiterate/primary $(\mathrm{n}=62)$ & 29 & 12 & $\mathrm{p}=0.585$ \\
Lower/secondary $(\mathrm{n}=17)$ & 2 & 5 & \\
Upper secondary $(\mathrm{n}=18)$ & & & \\
Tertiary (n=7) & & & \\
\hline
\end{tabular}

*: denotes significant value. nicity, source of referral, inpatient/outpatient status and level of education (table 1).

The experience of having undergone a previous endoscopy or bronchoscopy, the doctors' explanation and the patients' knowledge and understanding of the procedure and its indication made little impact on allaying the fears of the patients (table 2). Doctors were significantly more likely to explain the indication for bronchoscopy than how it would be performed $\left(\chi^{2}=6.403 ; p=0.011\right)$. Patients were significantly more likely to understand the indication for bronchoscopy than how it would be performed $\left(\chi^{2}=21.505\right.$; $\mathrm{p}<0.001)$. There was a positive correlation between doctors' explanation and patients' understanding of both the "why" and "how" of bronchoscopy ( $\mathrm{r}=0.8 ; \mathrm{p}<0.001$; and $r=0.565 ; p<0.001$, respectively). Eighty four patients preferred to be sedated, and they were divided equally between the "fearful" and "no fear" groups $\left(\chi^{2}=0.765\right.$; $=$ 0.386).

\section{Discussion}

The results of this study show that doctors' explanations about the bronchoscopy procedure and previous personal experience of an endoscopic procedure have little impact on allaying the fears of patients undergoing fibreoptic bronchoscopy. Fear of bronchoscopy was not influenced by the patients' demographic features, except for age and gender. Older patients were less likely to be fearful in this study. The elderly appeared to accept invasive procedures with a better degree of stoicism and self-control. In accordance with the findings by LevY et al. [6], female patients were more likely to be anxious.

Patients' fear of invasive diagnostic procedures is one aspect of patient care that physicians should attempt to alleviate [7]. One of the most important contributory factors is poor communication between doctor and patient [8]. Provision of a detailed explanation and description of an intended invasive procedure is considered to be the physician's duty and the patient's right. Most patients undergoing a fibreoptic bronchoscopy are anxious [9-11]. Various methods for reducing anxiety, including patient education and patient information leaflets, have been used in endoscopic procedures $[12,13]$. It has been shown that little or no sedation is required for those patients undergoing an endoscopic procedure if their fears are allayed by careful discussion or provided with an adequate explanation of the impending procedure [5, 14]. MENDES DE LEON et al. [11] noted that fear of the possible diagnosis of cancer $(23 \%)$ and dyspnoea or asphyxiation $(14 \%)$ were the main

Table 2. - The effect of previous endoscopic experience, understanding and explanation given to "no fear" and "fearful" patients undergoing bronchoscopy

\begin{tabular}{llccc}
\hline & & \multicolumn{2}{c}{ Patients } & \\
& & No fear & Fearful & Significance \\
\hline No previous endoscopy $(\mathrm{n}=77)$ & 29 & 48 & $\chi^{2}=1.660$ \\
Previous endoscopy (all types) $(\mathrm{n}=27)$ & 14 & 13 & $\mathrm{p}=0.195$ \\
Explained how: & Yes (n=69) & 29 & 40 & $\chi^{2}=0.039$ \\
& No $(\mathrm{n}=35)$ & 14 & 21 & $\mathrm{p}=0.837$ \\
Understood how: & Yes $(\mathrm{n}=56)$ & 21 & 35 & $\chi^{2}=0.740$ \\
& No $(\mathrm{n}=48)$ & 22 & 26 & $\mathrm{p}=0.394$ \\
Explained why: & Yes $(\mathrm{n}=85)$ & 34 & 51 & $\chi^{2}=0.348$ \\
& No $(\mathrm{n}=19)$ & 9 & 10 & $\mathrm{p}=0.563$ \\
Understood why: & Yes $(\mathrm{n}=87)$ & 35 & 52 & $\chi^{2}=0.273$ \\
& No $(\mathrm{n}=17)$ & 8 & 9 & $\mathrm{p}=0.608$ \\
\hline
\end{tabular}


anxieties of the $68 \%$ of patients who indicated considerable fear several days before bronchoscopy. In the present study, 58\% were fearful and the fear of pain and breathing difficulties were the most common fears. Only two patients were worried about their bronchoscopic findings and its implications. It may be due to the timing of the interview (20-30 min prior to bronchoscopy) that they were more concerned about the actual procedure that they were about to undergo than the possible findings from this diagnostic procedure.

The doctors in this study were more likely to explain the reason for the bronchoscopy than how it would be performed. Although there was a positive correlation between the doctors' explanation and the patients' understanding of "why" and "how" the procedure is carried out, the large number of "fearful" patients who were fearful of pain and breathing difficulties suggests that insufficient information was given about the likely sensations to be experienced during the procedure. Knowledge of these fears will allow the physician to provide appropriate information to allay some of the anxieties that the patient may not express. Levy et al. [6] showed that a detailed description of the procedure prior to endoscopy did not diminish patients' fears. It appears that providing information about the procedure is insufficient, and detailed information about the likely sensations that may be experienced during the procedure is required to reduce anxiety.

Specific information has been found to be more helpful for most patients, but for those patients who do not cope in an active fashion, the reverse seems true [15]. This points to the importance of relating the type of information to the needs and personality of the patient. Identifying the fears of these patients will allow physicians an opportunity to reassure patients more effectively and, thus, reduce the anxiety preceding bronchoscopy. A subsequent study should be performed to assess the effectiveness of this intervention.

Acknowledgements: The authors acknowledge, with thanks, the helpful comments of P. d'A. Semple and A.J. Peacock in the preparation of this paper.

\section{References}

1. Wilson-Barnett J. In: Stress in Hospital: Patients' Psychological Reactions to Illness and Healthcare. Edinburgh,
Churchill Livingstone, 1979; pp. 55-60.

2. Johnson JE, Rice VH. Sensory and distress components of pain. Nurs Res 1974; 23: 203-208.

3. Johnson JE, Kirchhoff NT, Endress MP. Altering children's distress behaviour during orthopaedic cast removal. Nurs Res 1975; 24 (6): 404-410.

4. Weinman J. Psychological interventions for stressful medical procedures. In: An Outline of Psychology as Applied to Medicine. 2nd Edn. Bristol, Wright, 1987; pp. 213-216.

5. Johnson JE, Morrissey JF, Leventhal H. Psychological preparation for an endoscopic examination. Gastrointest Endosc 1973; 19: 180-182.

6. Levy N, Landmann L, Stermer E, et al. Does a detailed explanation prior to gastroscopy reduce the patient's anxiety? Endoscopy 1989; 21: 263-265.

7. Wilson-Barnett J. The experience of a special test. In: Stress in Hospital: Patients' Psychological Reactions to Illness and Healthcare. Edinburgh, Churchill Livingstone, 1979; pp. 45-55.

8. Korsch BM, Negrete VF. Doctor-patient communication. Sci Am 1972; 227: 66-72.

9. Clarke SW. Fibreoptic bronchoscopy (Letter). $\mathrm{Br} \mathrm{Med} \mathrm{J}$ 1974; 3(5933): 740.

10. Robb Z. Bronchoscopy. Med J Aust 1991; 154(10): 682.

11. Mendes de Leon C, Bezel R, Karrer W, Brandli O. Premedication in fibreoptic bronchoscopy from the patient's and the physician's viewpoint: a randomized study for the comparison of midazolam and hydrocodone. Schweiz Med Wochenschr 1986; 116(37): 1267-1272.

12. Wilson JF, Moore RW, Randolph S, Hanson BJ. Behavioural preparation of patients for gastrointestinal endoscopy: information, relaxation and coping style. J Human Stress 1982; 8: 13-23.

13. Lanius M, Zimmermann P, Heegewaldt $\mathrm{H}$, et al. Does an information booklet on gastrointestinal endoscopy reduce anxiety for these examinations? Results of a randomized study with 379 patients. Z Gastroenterol 1990; 28(12): 651-655.

14. Hoare AM, Hawkins CF. Upper gastrointestinal endoscopy with or without sedation: patients opinions. $\mathrm{Br} \mathrm{Med}$ $J$ 1976; ii: 20.

15. Weinberger DA, Schwartz GE, Davidson RJ. Low-anxious, high-anxious and repressive coping styles: psychometric patterns and behavioral and psychological responses to stress. J Abnorm Psych 1979; 88: 369. 